\title{
Preparation of ursodeoxycholic acid from 7-ketone lithocholic acid by stereoselective electroreduction
}

\author{
Xiaomei Huang and Xuejun Cao*
}

\begin{abstract}
Background: Ursodeoxycholic acid (UDCA) is an important clinical drug in the treatment of liver disease. In previous work, ursodeoxycholic acid was prepared by traditional organic synthesis. The preparation of ursodeoxycholic acid through an electrochemical method with higher stereoselectivity and environmental friendliness is described herein.

Results: Dimethyl sulfoxide (DMSO), dimethylformamide (DMF), and N-methyl-2-pyrrolidone (NMP) were used as stereoselectivity additives during electroreduction. With $107.5 \mathrm{mM}$ DMSO in methanol containing potassium bromide and a continuous current of $20 \mathrm{~mA}$, 936 Coulombs was passed into the electrolysis system, achieving $88.5 \%$ conversion of 7-ketone lithocholic acid (7K-LCA), while the yield of UDCA reached $72.8 \%$. Cyclic voltammetry (CV) was used to explore the electrochemical behavior of the reaction, and the electrolysis results were consistent with the cyclic voltammograms.

Conclusions: Ursodeoxycholic acid can be prepared by electroreduction with high stereoselectivity. The method developed here offers a potential application for large-scale production of ursodeoxycholic acid and an interesting reference to asymmetric electrochemical reduction of the keto group.
\end{abstract}

Keywords: 7-Ketolithocholic acid; Ursodeoxycholic acid; Stereoselective; Electroreduction

\section{Background}

Ursodeoxycholic acid ( $3 \alpha, 7 \beta$-2-hydroxy-5 $\beta$-bile acid, UDCA) was first found by Shoda [1] in the bile of a black bear. It is used as a clinical drug in the treatment of gallstones, cholecystitis, PBC, and PSC and has broad market prospects and important scientific research value [2-9]. Kanazawa et al. [10] first synthesized ursodeoxycholic acid in 1954 by reducing 7 -ketolithocholic

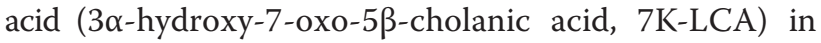
$n$-propyl alcohol by using metallic sodium with a $14 \%$ yield. At present, the industrial production of ursodeoxycholic acid is based on the synthesis process outlined by Kanazawa. Bharucha and Slemon [11] demonstrated that 7K-LCA could be reduced to UDCA in an electrolyte containing short-chain alcohol, preferably with weakly acidic dipolar additives such as hexamethylphosphoric triamide (HMPA) with ruthenized titanium or

\footnotetext{
* Correspondence: caoxj@ecust.edu.cn

State Key Laboratory of Bioreactor Engineering, Department of Bioengineering, East China University of Science and Technology, 130 Meilong Rd., Shanghai 200237, China
}

mercury electrodes, and a $91 \%$ yield of UDCA could be obtained. Magni et al. [12] stated that a $97 \%$ yield of UDCA could be obtained by catalytic hydrogenation of $3 \alpha$-hydroxy-7-oxo-5 $\beta$-cholanate using Raney nickel as the catalyst and beta-branched alcohols as the solvent in the presence of a base at $40{ }^{\circ} \mathrm{C}$ and atmospheric pressure. $3 \alpha$-Hydroxy-7-oxo-5 $\beta$-cholanate dissolved in alcohols could also be reduced to UDCA by hydrogen at a pressure of $0.5 \mathrm{MPa}$ and a temperature of $80{ }^{\circ} \mathrm{C}$ catalyzed by Raney nickel, giving a $92.5 \%$ yield of UDCA [13]. In addition, some biological methods are developed in recent years and showed high potential for industrial application $[14,15]$. Herein, $3 \alpha$-hydroxy-7-oxo- $5 \beta$-cholanate was formed by adding hydrate to 7K-LCA. Currently, there have been very few reports on the preparation of ursodeoxycholic acid by an electrochemical method, despite the fact that it is a relatively simple and safe process that does not require harsh reaction conditions or complicated reaction steps.

Electrochemical reduction of carbonyl compounds has progressed considerably during the past 20 years, not only 


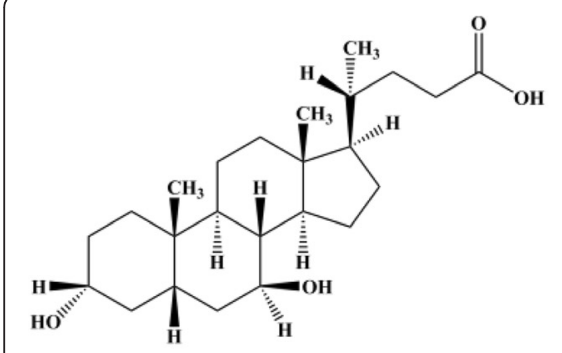

UDCA

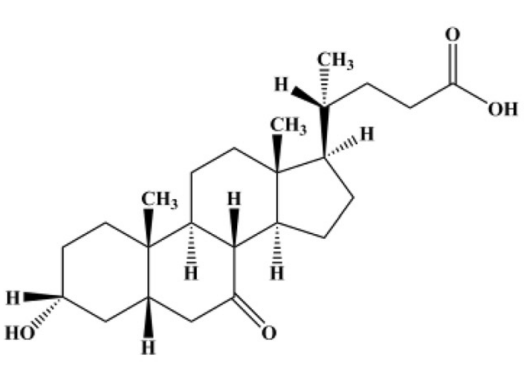

7K-LCA

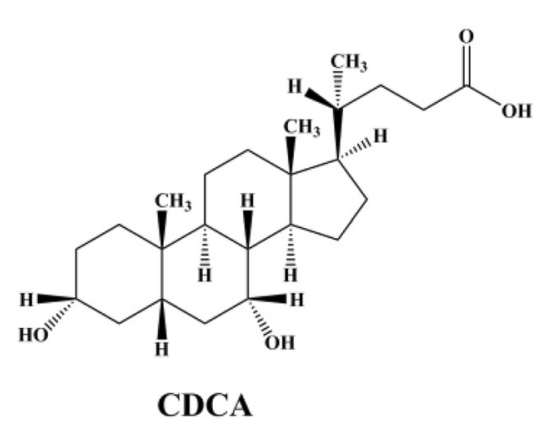

CDCA

Fig. 1 The chemical structures of UDCA, 7K-LCA, and CDCA

in theory but also in application. A number of methods for creating a chiral environment have been reported using electrochemical stereoselective synthesis, such as the use of chiral solvents [16-18], chiral supporting electrolytes [17-20], intrinsic optical substrate conformation [19], chiral electrodes [21-23], and chiral catalytic systems [24, 25]. In the previous work [26], our group synthesized 7ketolithocholic acid, which is an important intermediate in ursodeoxycholic acid synthesis, by indirect electrooxidation. Herein, we describe our attempts to prepare ursodeoxycholic acid through electroreduction. The electroreduction of ketone in the presence of a hydrogen source produces two main products: ursodeoxycholic acid and chenodeoxycholic acid (CDCA). During electrolysis of 7-ketolithocholic acid, the preferred predominantly chenodeoxycholic acid, with only small amounts of ursodeoxycholic acid, is formed. However, UDCA can be obtained stereoselectively in the presence of an aprotic polar solvent (Fig. 1).

The purpose of this paper was to electroreduce 7ketolithocholic acid stereoselectively into ursodeoxycholic acid in a solution comprising a highly polar and aprotic solvent [dimethyl sulfoxide (DMSO), dimethylformamide (DMF), and $N$-methyl-2-pyrrolidone (NMP)]. With the correct amount of aprotic solvent, the $\mathrm{C}-7$ carbonyl group of $7 \mathrm{~K}-\mathrm{LCA}$ can be selectively converted into a $7 \beta$-hydroxy group on the cathode surface. Experiments show that the aprotic solvent can significantly increase the conversion of 7-ketolithocholic acid and the yield of ursodeoxycholic acid, perhaps indicating the asymmetric reduction of the keto group.

\section{Methods}

\section{General methods}

UDCA (99 \%) was purchased from Aladdin Chemistry Co. Ltd. 7K-LCA was prepared according to our previous work, via indirect electrooxidation of CDCA using a $\mathrm{Br}^{-} / \mathrm{Br}_{2}$ cycle. Methanol and potassium bromide were from Sinopharm Chemical Reagent Co. Ltd. (Shanghai, China). Acetonitrile [high-performance liquid chromatography (HPLC) grade] was from Shanghai Xingke Biochemistry Co. Ltd. (Shanghai, China). All other reagents were of analytical grade, from the Shanghai Ling Feng Chemical Reagent Co. Ltd. (Shanghai, China). WY-30.5 DC power with a single regulator constant flow was from Shanghai Starfish Instrument Co. Ltd. (Shanghai, China). A H-divided electrolytic cell was manufactured by the Glass Instrument Factory of the East China University of Science and Technology (ECUST, Shanghai, China). Cathode material consisting of a high-purity lead plate electrode was obtained from the Engineering Training Center of ECUST. The size of the lead plate was $145 \times 30 \mathrm{~mm}$. The anode material consisted of a titanium-ruthenium mesh electrode from Henan Xinxiang Future Water Chemical Co. Ltd. (Xingxiang, Henan). The size of the titanium-ruthenium mesh electrode was $145 \times 30 \mathrm{~mm}$. A HF-101 fluoroplastic cation exchange membrane was purchased from the Shanghai Hua Kai Technology Company

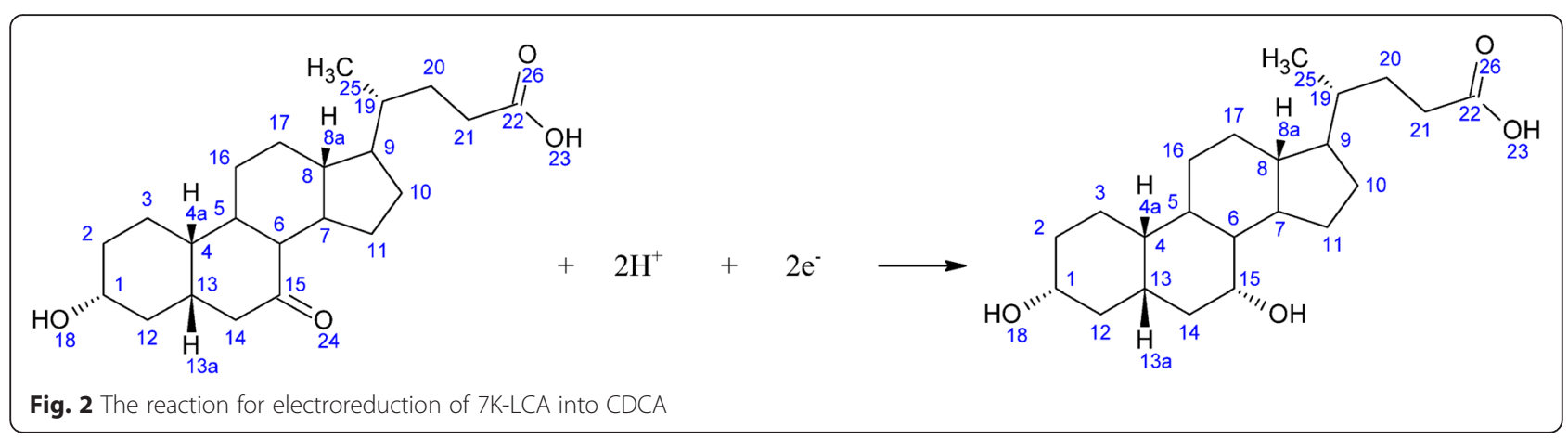




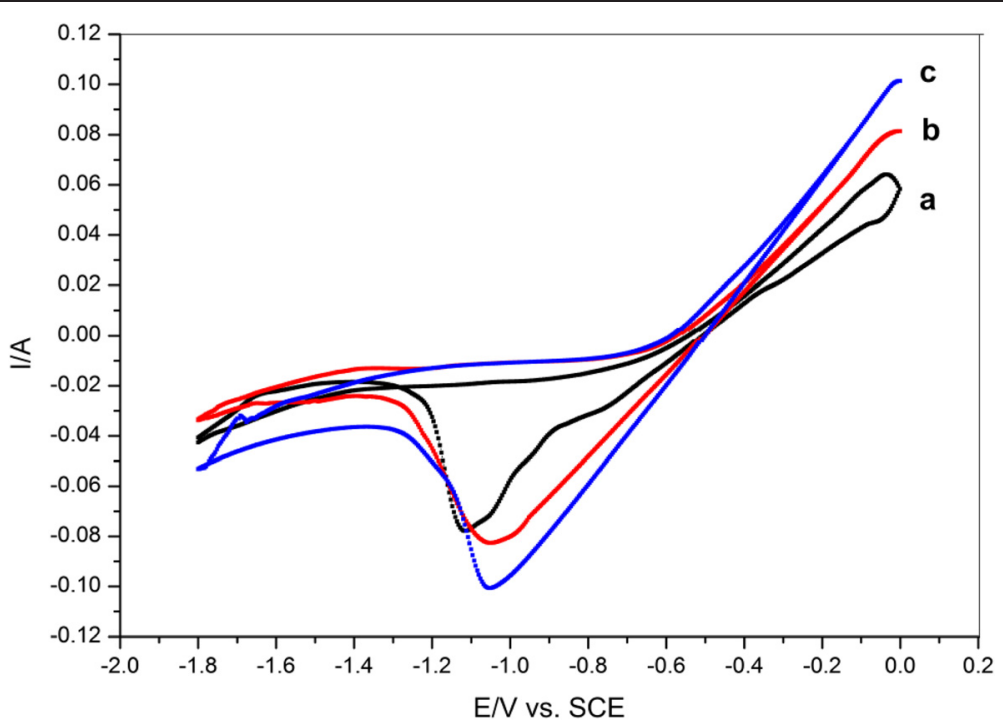

Fig. 3 Cyclic voltammograms of $0.04 \mathrm{M} 7 \mathrm{~K}-\mathrm{LCA}$ in the solvent with $0.08 \mathrm{M} \mathrm{KBr}$ at different scan rates: (a) $10 \mathrm{mV} \mathrm{s}^{-1}$, (b) $50 \mathrm{mV} \mathrm{s}^{-1}$, and (c) $100 \mathrm{mV} \mathrm{s}$, $T=65^{\circ} \mathrm{C}$. The solvent was $130 \mathrm{ml}$ of co-solvent $\left(\mathrm{MeOH} / \mathrm{H}_{2} \mathrm{O}=9.83 / 1\right.$, volume ratio)

(Shanghai, China). A cyclic voltameter with a PARSTAT 2273 electrochemical workstation (Princeton Applied Research, Princeton, NJ, USA) was used to measure cyclic voltammograms.

\section{Electroanalytical procedure}

The electroanalytical experiments were carried out in an electrochemical workstation with a co-solvent $(\mathrm{MeOH} /$ $\mathrm{H}_{2} \mathrm{O}=9.83 / 1$, volume ratio) containing $0.08 \mathrm{M}$ potassium bromide as the supporting electrolyte in a divided glass cell, with a lead plate as the working electrode, a titanium- ruthenium mesh as the counter electrode, and $\mathrm{Ag}|\mathrm{AgCl}| \mathrm{KCl}$ as the reference electrode. All experiments were performed at $65{ }^{\circ} \mathrm{C}$ under atmospheric pressure. In addition, oxygen was removed from the solution by continuous bubbling with nitrogen before the experiment.

\section{Selective electroreduction of 7K-LCA}

The galvanostatic electrolysis was carried out in a $\mathrm{H}$ divided electrolytic cell with the HF-101 cation exchange membrane, and the reaction systems consisted of $0.04 \mathrm{M}$ substrate 7-ketone lithocholic acid, 0.08 M supporting

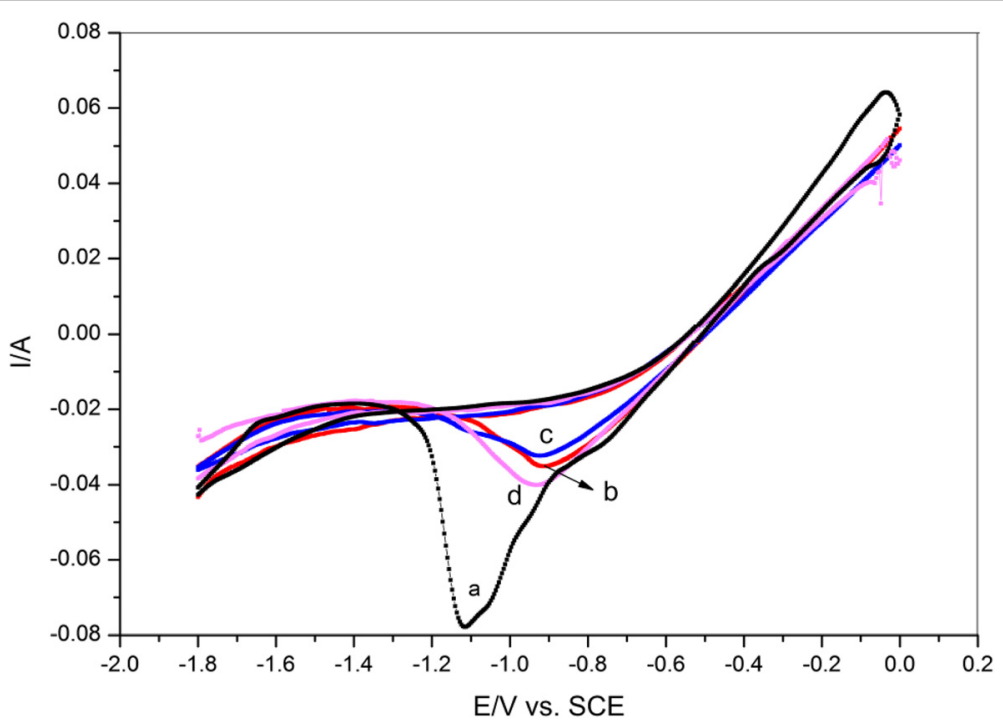

Fig. 4 Cyclic voltammograms recorded at the lead electrode at $65^{\circ} \mathrm{C}$ at a scan rate of $10 \mathrm{mV} \mathrm{s}^{-1}$ : (a) blank cyclic voltammetry in the solvent with $0.08 \mathrm{M} \mathrm{KBr}$, (b) as $(a)+0.12 \mathrm{M} \mathrm{DMSO}$, (c) as (a) + 0.36 M DMSO, and (d) as (a) + 0.6 M DMSO. The solvent was $130 \mathrm{ml}$ of co-solvent $\left(\mathrm{MeOH} / \mathrm{H}_{2} \mathrm{O}=9.83 / 1\right.$, volume ratio) 
Table 1 Influence of DMSO on the stereoselective electroreduction of 7K-LCA

\begin{tabular}{llllc}
\hline No. & DMSO content (mM) & $\begin{array}{l}\text { Supporting } \\
\text { electrolyte }\end{array}$ & $\begin{array}{l}\text { Conversion of } \\
\text { 7K-LCA }\end{array}$ & $\begin{array}{l}\text { Yield of } \\
\text { UDCA }^{\mathrm{a}}(\%)\end{array}$ \\
\hline 1 & - & $\mathrm{KBr}$ & 48 & 18.8 \\
2 & 107.5 & $\mathrm{KBr}$ & 88.5 & 72.8 \\
3 & 317.6 & $\mathrm{KBr}$ & 92.5 & 16.6 \\
4 & 521.5 & $\mathrm{KBr}$ & 51.7 & 20.1 \\
\hline
\end{tabular}

Cathode: lead; anode: titanium-ruthenium mesh; 7K-LCA concentration: 0.04 $\mathrm{M}$; supporting electrolyte concentration: $0.08 \mathrm{M}$; current density: $2.1 \mathrm{~mA} \mathrm{~cm}{ }^{-2}$; temperature: $65^{\circ} \mathrm{C}$

${ }^{a}$ Conversion based on the starting material and the purity of UDCA determined by HPLC analysis electrolyte, and $0.12 \mathrm{M}$ aprotic solvent in a 131-ml co-solvent $\left(\mathrm{MeOH} / \mathrm{H}_{2} \mathrm{O}=9.83 / 1\right.$, volume ratio) bubbled with $\mathrm{N}_{2}$ to remove oxygen. A high-purity lead plate was used as the cathode and a titanium-ruthenium mesh as the anode. A continuous current of $20 \mathrm{~mA}$ was maintained during the reaction. After 936 Coulombs had passed through, the current was switched off. All experiments were carried out at $65^{\circ} \mathrm{C}$.

When the reaction was complete, the organic solvent from the catholyte was removed using a rotary evaporator to obtain a solid sample. It was then dissolved in $\mathrm{NaOH}$ solution, and the $\mathrm{pH}$ was adjusted to 2.0 using hydrochloric acid. The precipitate was collected by
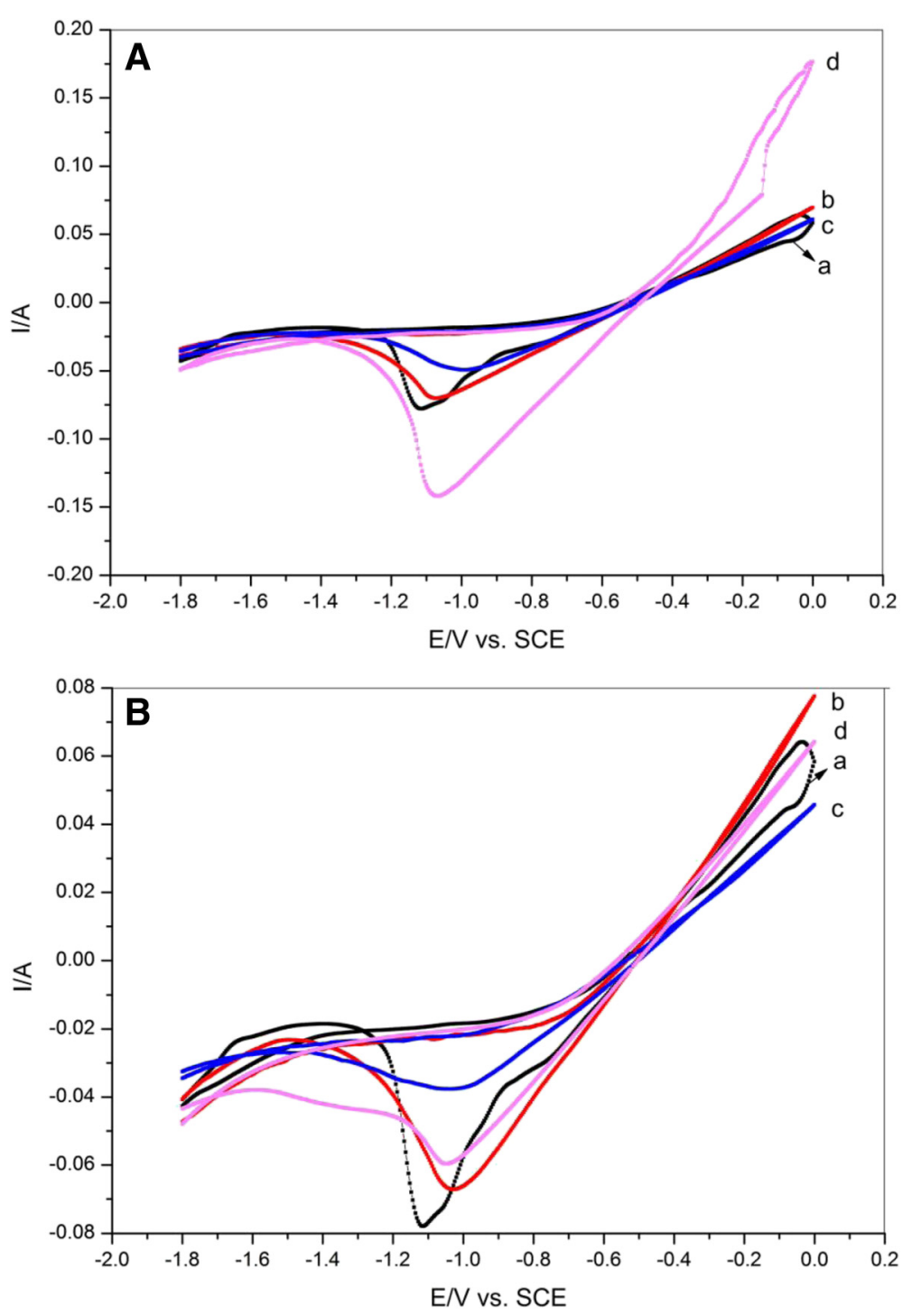

Fig. $5 \mathrm{Cyclic}$ voltammograms recorded at the lead electrode at $65^{\circ} \mathrm{C}$ at a scan rate of $10 \mathrm{mV} \mathrm{s}^{-1}$ : a (a) blank cyclic voltammetry in the solvent with $0.08 \mathrm{M} \mathrm{KBr}$, (b) as $(a)+0.11 \mathrm{M} \mathrm{DMF}$, (c) as $(a)+0.33 \mathrm{M} \mathrm{DMF}$, and (d) as (a) + $0.55 \mathrm{M} \mathrm{DMF.} \mathbf{b}(a)$ Blank cyclic voltammetry in the solvent with $0.08 \mathrm{M} \mathrm{KBr}$, (b) as $(a)+0.09 \mathrm{M} \mathrm{NMP}$, (c) as $(a)+0.26 \mathrm{M} \mathrm{NMP}$, and $(d)$ as $(a)+0.44 \mathrm{M} \mathrm{NMP}$. The solvent was $130 \mathrm{ml}$ of co-solvent $\left(\mathrm{MeOH} / \mathrm{H}_{2} \mathrm{O}=9.83 / 1\right.$, volume ratio) 
Table 2 Influence of aprotic polar solvent type on the stereoselective electroreduction of 7K-LCA

\begin{tabular}{lllll}
\hline No. & Aprotic solvent & Amount $(\mathrm{mM})$ & $\begin{array}{l}\text { Conversion of } \\
7 \mathrm{~K}-\mathrm{LCA}^{\mathrm{a}}(\%)\end{array}$ & $\begin{array}{l}\text { Yield of } \\
\text { UDCA }^{\mathrm{a}}(\%)\end{array}$ \\
\hline 1 & - & - & 48 & 18.8 \\
2 & DMSO & 107.5 & 88.5 & 72.8 \\
3 & DMF & 99.0 & 56.1 & 47.3 \\
4 & DMF & 292.6 & 68.5 & 65.4 \\
5 & DMF & 480.4 & 74.1 & 19.5 \\
6 & NMP & 79.0 & 57 & 11.3 \\
7 & NMP & 233.5 & 43 & - \\
8 & NMP & 383.3 & 21 & - \\
\hline
\end{tabular}

Cathode: lead; anode: titanium-ruthenium mesh; 7K-LCA concentration: 0.04 $\mathrm{M}$; supporting electrolyte concentration: $0.08 \mathrm{M}$; current density: $2.1 \mathrm{~mA} \mathrm{~cm}{ }^{-2}$; temperature: $65^{\circ} \mathrm{C}$

${ }^{a}$ Conversion based on the starting material and the purity of UDCA

determined by HPLC analysis

filtration and then dried in an oven. The final product was detected by HPLC.

\section{Scale-up of electrolysis}

During the scale-up of electrolysis, $6 \mathrm{~kg}$ of 7K-LCA was dissolved in $280 \mathrm{~kg}$ of methanol and $2.7 \mathrm{~kg}$ of $\mathrm{KBr}$ was dissolved in $24 \mathrm{~kg}$ of water; then, the two solutions were mixed and added to a hold-up vessel containing $6.5 \mathrm{~kg}$ of DMF, which was used as the catholyte. An equal volume of $5 \% \mathrm{H}_{2} \mathrm{SO}_{4}$ was used as the anolyte. A bipolar diaphragm electrolyzer comprised the reaction vessel separated by the HF-101 cation exchange membrane. A high-purity lead plate and titanium-ruthenium mesh were used as the cathode and anode, respectively. The effective overlap area of the electrodes was $70 \times 35 \mathrm{~cm}$. The electrolyte was pumped into the electrolyzer with a circulating pump before the reaction started. A continuous current of $20 \mathrm{~A}$ was used for electrolysis over $20 \mathrm{~h}$ at $55^{\circ} \mathrm{C}$. When the reaction was complete, the organic solvent from the catholyte was removed, and the final product was collected for detection.

\section{Analytical methods}

UDCA was analyzed by reversed phase HPLC, using a C-18 column with Welchrom-C18 $5-\mu \mathrm{m}$ resin in a $4.6 \times$ $150 \mathrm{~mm}$ column (Welch Material Inc., Shanghai, China). The HPLC instrument (LC-20A) was from Shimadzu

Table 3 The main condition of the scale-up electrolysis

\begin{tabular}{lllllll}
\hline Experiment & $\begin{array}{l}7 \mathrm{~K}-\mathrm{LCA} \\
(\mathrm{kg})\end{array}$ & $\begin{array}{l}\text { Methanol } \\
(\mathrm{kg})\end{array}$ & $\begin{array}{l}\mathrm{KBr} \\
(\mathrm{kg})\end{array}$ & $\begin{array}{l}\mathrm{H}_{2} \mathrm{O} \\
(\mathrm{kg})\end{array}$ & $\begin{array}{l}\mathrm{DMF} \\
(\mathrm{kg})\end{array}$ & $\begin{array}{l}\text { Temperature } \\
\left({ }^{\circ} \mathrm{C}\right)\end{array}$ \\
\hline 1 & 6 & 280 & 2.7 & 24 & 6.5 & 55 \\
2 & 6 & 280 & 2.7 & 24 & 6.5 & 45 \\
3 & 6 & 280 & 2.7 & 20 & 6.5 & 45 \\
4 & 6 & 280 & 2.7 & 20 & 6.5 & 55 \\
\hline
\end{tabular}

Corporation, Kyoto, Japan, and was used for quantitative analysis of the reaction products at $208 \mathrm{~nm}$. The mobile phase was a mixture of acetonitrile and phosphate acid buffer ( $\mathrm{pH}$ 3.0) with a volume ratio of 50:50 at a flow rate of $1.0 \mathrm{ml} / \mathrm{min}$ at $25{ }^{\circ} \mathrm{C}$. Fifty percent methanol was used to clean the syringe in the SIL-20A autosampler (Shimadzu Corporation, Kyoto, Japan). The conversion of $7 \mathrm{~K}$-LCA was calculated as $C=M_{\mathrm{t}} / M_{0} \times 100 \%$, where $M_{\mathrm{t}}$ is the amount of $7 \mathrm{~K}-\mathrm{LCA}$ consumed and $M_{0}$ is the total amount of 7K-LCA used during the electrolysis. The yield of UDCA was calculated as $Y=A_{\mathrm{r}} / A_{\mathrm{t}} \times 100 \%$, where $A_{\mathrm{r}}$ is the actual productivity of UDCA and $A_{\mathrm{t}}$ is the theoretical productivity of UDCA. The electrolysis product was purified by silylation crystallization [27].

\section{Results and discussion}

Stereoselective electrochemical reduction is important both in research and applications. In this electrochemical reaction, ursodeoxycholic acid was synthesized by electroreduction of 7-ketolithocholic acid under certain conditions.

During electrolysis, the C-7 carbonyl group of 7K-LCA is converted into a $7 \beta$-hydroxy group on the cathode surface. Two side reactions may exist in this system. In the first, the C-7 carbonyl group of 7K-LCA is converted to a $7 \alpha$-hydroxy group, and chenodeoxycholic acid is generated (Fig. 2). In the second, hydrogen is produced on the cathode surface. However, the added aprotic polar solvent can effectively suppress the generation of chenodeoxycholic acid.

\section{Electroanalytical results}

Cyclic voltammograms (CVs) of 7K-LCA using a lead electrode in methanol at different scan rates are shown in Fig. 3. These show that there is only one irreversible peak, located at $-1.2 \mathrm{~V}$, in the CVs from the positive to negative scan direction, at a scan rate of $10 \mathrm{mV} / \mathrm{s}$ (Fig. 3, curve a). This indicates that only the reduction process is taking place in the electrolysis system. From the results of the electrolysis reaction, this reduction peak may correspond to the reduction of the ketone group $(\mathrm{C}=\mathrm{O})$ of $7 \mathrm{~K}-\mathrm{LCA}$ because the main reaction is the conversion of the C-7 carbonyl group of 7K-LCA to a hydroxyl group. When the scan rate increased, the reduction peaks became more positive, with the peak current increasing concomitantly (Fig. 3, curves a-c).

To study the CVs of 7K-LCA in $\mathrm{MeOH}$ with $0.08 \mathrm{M}$ $\mathrm{KBr}$, a potential-controlled electrolysis experiment was carried out at $-1.2 \mathrm{~V}$, and a current-controlled electrolysis experiment was carried out at $60 \mathrm{~mA}$, because the electrolysis was an irreversible electrochemical reaction.

To further study the effect of the aprotic solvent on the voltammetric behavior of 7-ketolithocholic acid, DMSO was added into the co-solvent $(\mathrm{MeOH}$ with 0.08 $\mathrm{M} \mathrm{KBr}$ ). As shown in curves b-d in Fig. 4, the reduction 


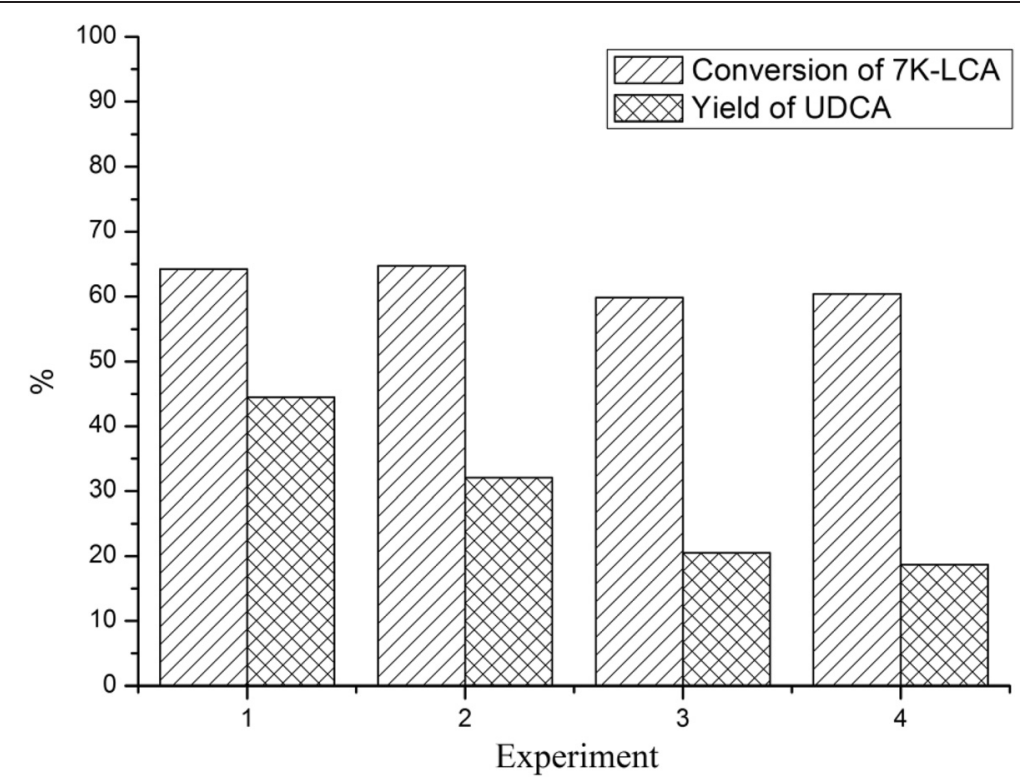

Fig. 6 The result of different electrolysis experiments during scale-up

peak potential shifted to a more positive value with increasing amount of DMSO. This indicates strong interactions between DMSO and the 7-ketolithocholic acid, under which the peak potential shifted from -1.116 to $-0.920 \mathrm{~V}$. This is a suitable electroreduction condition for 7-ketolithocholic acid. Presumably, DMSO influenced the adsorption of 7K-LCA on the cathode interface and changed the structure of the electric double layer $[28,29]$.

\section{Preparative electrolysis}

Preparative electrolysis was carried out in a reaction system consisting of co-solvent $\left(\mathrm{MeOH} / \mathrm{H}_{2} \mathrm{O}=9.83 / 1\right)$, $0.08 \mathrm{M} \mathrm{KBr}, 0.04 \mathrm{M} 7 \mathrm{~K}-\mathrm{LCA}$, and $0.12 \mathrm{M} \mathrm{DMSO}$ in a divided cell equipped with a lead plate cathode and a titanium-ruthenium mesh anode at $65{ }^{\circ} \mathrm{C}$. A continuous current of $20 \mathrm{~mA}$ was applied, and after 936 Coulombs had passed through, the current was switched off. The organic solvent from the catholyte was removed using a rotary evaporator to obtain a solid sample. It was then dissolved in $\mathrm{NaOH}$ and the $\mathrm{pH}$ was adjusted to 2.0 using hydrochloric acid. The precipitate was collected by filtration and dried in an oven.

\section{The influence of DMSO on the yield of UDCA and conversion ratio of $7 \mathrm{~K}-\mathrm{LCA}$}

Table 1 presents the conversion of 7K-LCA and yield of UDCA with different amounts of DMSO. The electrolysis reaction without DMSO gave a 48 \% 7K-LCA conversion and $18.8 \%$ UDCA yield. Addition of $107.5 \mathrm{mM}$ DMSO promoted the reduction of the $\mathrm{C}-7$ carbonyl group of 7K-LCA, and the best results obtained give a $72.8 \%$ UDCA yield and an $88.5 \%$ 7K-LCA conversion. However, the yield of UDCA diminished with greater amounts of DMSO. It can be concluded from the experimental results that DMSO is beneficial to the reduction of the C-7 carbonyl group of 7K-LCA. Compared with the electrolysis in the absence of DMSO, the conversion of 7K-LCA rose from 48 to $88.5 \%$, and the yield of UDCA increased from 18.8 to $72.8 \%$ which clearly means that the C-7 carbonyl group of 7K-LCA was selectively converted into the $7 \beta$-hydroxy group. However, higher amounts did not further promote the reaction, causing a higher resistance during electrolysis to be observed.

\section{Influence of aprotic polar solvent type on the yield of UDCA and conversion ratio of 7K-LCA}

As shown in Fig. 5a, the peak potential exhibited a positive shift (curves b-d in Fig. 5a) caused by the addition of DMF, while the increase in the 7-ketolithocholic acid reduction peak current can be ascribed to a higher resistance. In Fig. 5b, the peak potential of 7-ketolithocholic acid reduction was also shifted to a more positive position compared with the blank cyclic voltammetry in the solvent with 0.08 $\mathrm{M} \mathrm{KBr}$, but the peak current showed a minimal increase, in contrast to the increase shown in Fig. 5a.

These results indicate that the addition of aprotic solvent was favorable to the electroreduction of 7-ketolithocholic acid, and the mechanism is similar to the situation when DMSO is added. However, different types of aprotic solvent have different influences on the reduction, and the addition of aprotic solvents changed the resistance, dielectric constant, and polarity of the electrolyte, which may lower the current efficiency. 
$\mathrm{mV}$

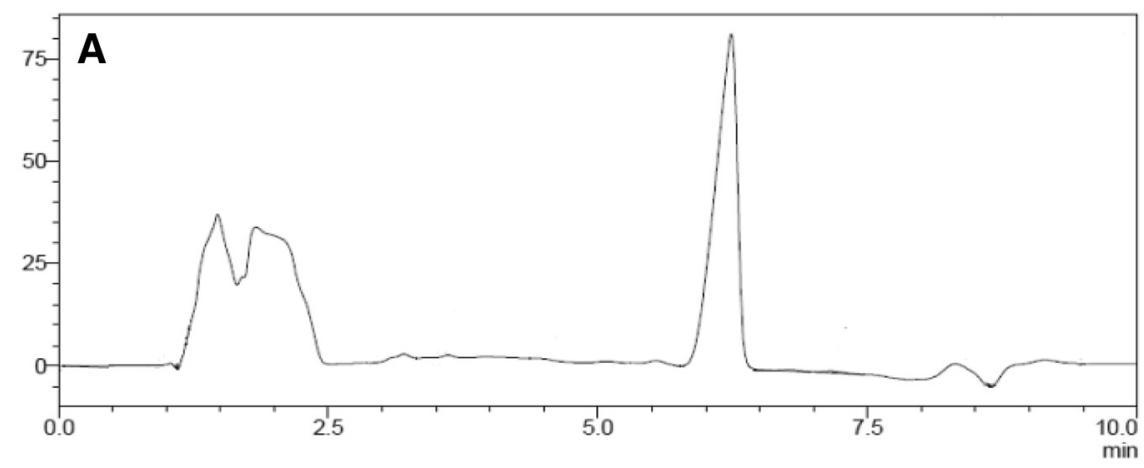

$\mathrm{mV}$

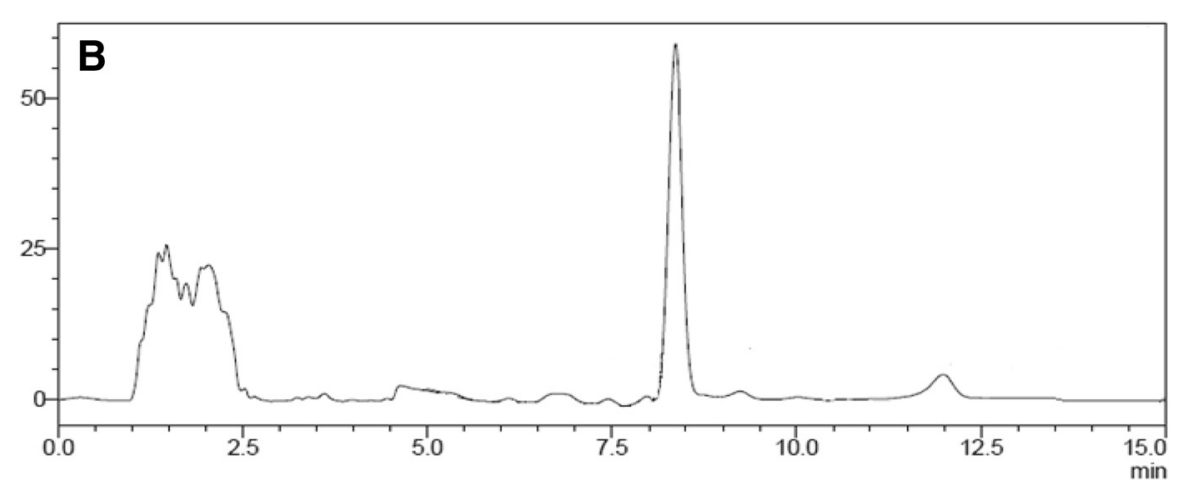

$\mathrm{mV}$

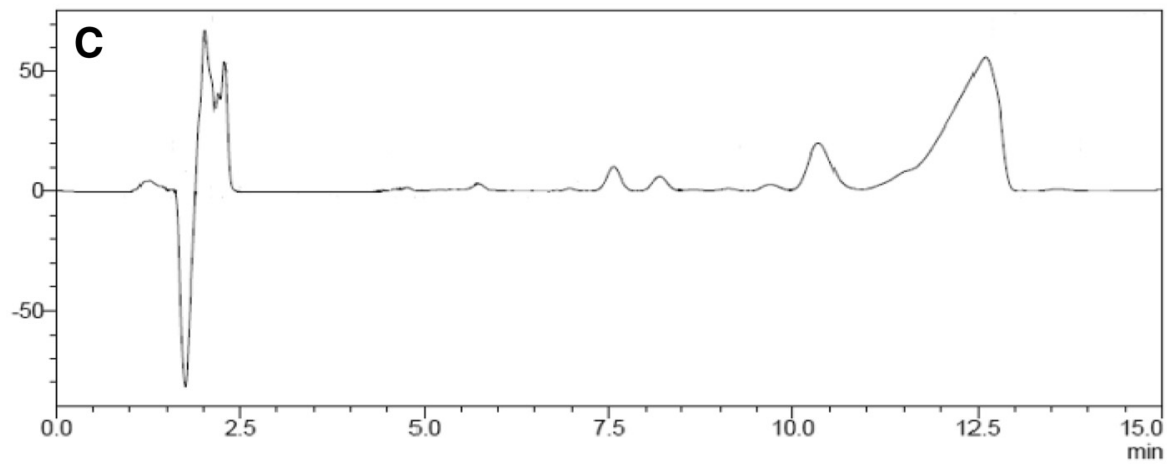

$\mathrm{mV}$

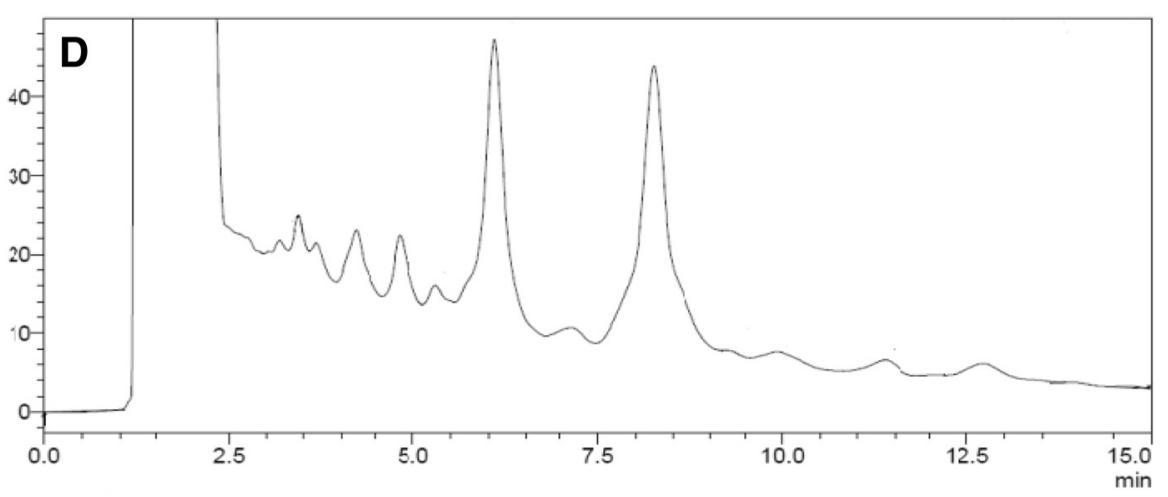

Fig. $7 \mathrm{HPLC}$ chromatogram of the product and its external standard. a HPLC chromatogram of UDCA. b HPLC chromatogram of 7K-LCA. c HPLC chromatogram of CDCA. $\mathbf{d}$ HPLC chromatogram of the product 
Table 2 (No. 2-8) presents the results using different aprotic solvents (DMSO, DMF, NMP). With DMSO, the yield of UDCA reached $72.8 \%$, and the conversion of 7-ketolithocholic acid was $88.5 \%$. When DMSO was replaced by DMF, the conversion of $7 \mathrm{~K}-\mathrm{LCA}$ was augmented by an increase in the amount of DMF, but the yield of UDCA first increased and then decreased. Comprehensively considering the conversion of $7 \mathrm{~K}-\mathrm{LCA}$ and the yield of UDCA, $292.6 \mathrm{mM}$ DMF was perhaps the best choice, with a $68.5 \% 7 \mathrm{~K}-\mathrm{LCA}$ conversion ratio and a $65.4 \%$ yield of UDCA. When adding NMP, at $79.0 \mathrm{mM}$ NMP, the conversion ratio of $7 \mathrm{~K}-\mathrm{LCA}$ was $57 \%$, but the yield of UDCA was only $11.3 \%$. With an increased amount of NMP, 7K-LCA can be transformed, but the target product UDCA could not be produced. In addition, Table 2 (No. 1-8) reveals that the addition of aprotic solvents improves the product yield, consistent with the cyclic voltammograms shown in Fig. 5. However, the amount of aprotic solvent used has a different effect on the yield of UDCA.

\section{Scale-up of electrolysis}

In prior experiments, DMSO shows better results compared with DMF obviously. However, considering the solvent in separation by silylation crystallization and the price of raw materials, we chose DMF as the additive in the scale-up electrolysis.

During the scale-up of electrolysis, four experiments were conducted. Table 3 presents the main information of the four experiments. After considering the condition of scale-up, we changed the temperature and water content. As shown in Fig. 6, in the first experiment of scale-up, the $7 \mathrm{~K}-\mathrm{LCA}$ conversion reached $64.2 \%$ and the UDCA yield was $44.5 \%$, but the other experiments gave lower UDCA yield. UDCA yield of the last experiment was $18.7 \%$, less than half of the first experiment. This result was lower than the electrolysis with $292.6 \mathrm{mM}$ DMF in the laboratory significantly. There are two possible reasons for this result, evaporation of the solvent and the use of impure reused solvent. In our previous work, the water content of the electrolyte has great influence on the electrolysis result [30]. We intend to optimize the electrolyte in future research.

\section{Characterization of the product}

The product was determined by HPLC after purification and drying. As shown in Fig. 7, the retention times of UDCA and 7K-LCA were 6.0 and $8.2 \mathrm{~min}$, respectively. Many impurity peaks can be seen between 2.0 and $6.0 \mathrm{~min}$, and some of the corresponding materials were likely contained in the raw material and others were produced by the electroreduction process. The yield of UDCA was calculated to reach $72.8 \%$.

\section{Conclusions}

In summary, the electrochemical stereoselective reduction of 7-ketolithocholic acid into UDCA was conducted using aprotic polar solvents. A higher conversion $(88.5 \%)$ of 7-ketolithocholic acid was observed with a $72.8 \%$ yield of ursodeoxycholic acid upon addition of 107.5 $\mathrm{mM}$ DMSO during the electrolysis process. In the preliminary scale-up, the conversion of 7K-LCA reached $64.2 \%$ and the UDCA yield was $44.5 \%$. Compared with chemical and biological preparative processes, the electrochemical process offers the advantages of low cost, high stereoselectivity, and production safety.

\section{Competing interests}

The authors declare that they have no competing interests.

\section{Authors' contributions}

$\mathrm{XH}$ designed the study, collected, processed, and analyzed the data, and wrote the article. XC contributed to the study design and article corrections. Both authors read and approved the final manuscript.

Received: 13 April 2015 Accepted: 10 June 2015

Published online: 26 June 2015

\section{References}

1. Shoda M (1927) Über die ursodesoxycholsäure aus bärengallen und ihre physiologische wirkung. J Biochem 7(3):505-517

2. Talwalkar JA, Lindor KD (2003) Primary biliary cirrhosis. Lancet 362(9377):53-61

3. European Association for the Study of the Liver (2009) EASL clinical practice guidelines: management of cholestatic liver diseases. J Hepatol 51(2):237-267

4. Salvioli G, Igimi H, Carey MC (1983) Cholesterol gallstone dissolution in bile. Dissolution kinetics of crystalline cholesterol monohydrate by conjugated chenodeoxycholate-lecithin and conjugated ursodeoxycholate-lecithin mixtures: dissimilar phase equilibria and dissolution mechanisms. J Lipid Res 24:701-720

5. Shiraki K, Ito T, Sugimoto K et al (2005) Different effects of bile acids, ursodeoxycholic acid and deoxycholic acid, on cell growth and cell death in human colonic adenocarcinoma cells. Int J Mol Med 16(4):729-733

6. Liu F, Cheng Y, Wu J et al (2006) Ursodeoxycholic acid differentially affects three types of sphingomyelinase in human colon cancer Caco 2 cells. Cancer Lett 235(1):141-146

7. Galsky J, Bansky G, Holubova T et al (1999) Effect of ursodeoxycholic acid in acute viral hepatitis. J Clin Gastroenterol 28(3):249-253

8. Poupon RE, Lindor KD, Cauch DK et al (1997) Combined analysis of randomized controlled trials of ursodeoxycholic acid in primary biliary cirrhosis. Gastroenterol 113(3):884-890

9. Santos VN, Lanzoni VP, Szejnfeld J et al (2003) A randomized double-blind study of the short-time treatment of obese patients with nonalcoholic fatty liver disease with ursodeoxycholic acid. Braz J Med Biol Res 36(6):723-729

10. Kanazawa T, Shimazaki A, Sato T et al (1954) Syntheses of ursodeoxycholic acid and its conjugated bile acid. Proc Jpn Acad 30(5):391-392

11. Bharucha KR, Slemon CE (1985) Process for the electrochemical reduction of 7-ketolithocholic acid to ursodeoxycholic acid., US 4547271

12. Magni A, Piccolo O, Ascheri A (1987) Stereoselective reduction of the keto group at 7-position of a bile keto acid., EP 0230085

13. Hattori M, Mikami K, Sekine T (1993) Selective reduction of bile acid having keto group at 7-site., JP 5032692

14. Liu L, Braun M, Gebhardt G, Weuster-Botz D, Gross R, Schmid R (2013) One-step synthesis of 12-ketoursodeoxycholic acid from dehydrocholic acid using a multienzymatic system. Appl Microbiol Biotechnol 97:633-639

15. Zheng MM, Wang RF, Li CX, Xu JH (2015) Two-step enzymatic synthesis of ursodeoxycholic acid with a new $7 \beta$-hydroxysteroid dehydrogenase from Ruminococcus torques. Process Biochem 50:598-604

16. Seebach D, Oei HA (1975) Mechanism of electrochemical pinacolization. The first asymmetric synthesis in a chiral medium. Angew Chem internat Edit 14(9):634-636

17. Horner L, Degner D (1974) Studien zum vorgang der wasserstoffübertragung-33. Zur kenntnis des aufbaus der elektrochemischen doppelschicht. Die 
asymmetrische elektrochemische reduktion einiger alkyl-phenyl-ketone in gegenwart optisch aktiver leitsalze. Electrochim Acta 19(10):611-627

18. Horner L, Brich W (1978) Studien zum vorgang der wasserstoffübertragung 49: zur frage der auslösung einer optischen induktion durch anwendung optisch aktiver ephedrinderivate und optisch aktiver kronenether als leitsalze bei der elektroreduktion von acetophenon. Chem Ber 111(2):574-578

19. Schuster C, Knollmueller M, Gaertner P (2006) Chiral linker. Part 4: diastereoselective addition of RZnX to a-keto esters using m-hydrobenzoin derived chiral auxiliaries in solution and on solid support and their application in the stereo-selective synthesis of frontalin. Tetrahedron: Asymmetry 17(16):2430-2441

20. Chen BL, Xiao Y, Xu XM, Yang HP, Wang H, Lu JX (2013) Alkaloid induced enantioselective electroreduction of acetophenone. Electrochim Acta 107:320-326

21. Yadav AK, Manju M, Chhinpa PR (2003) Enantioselective cathodic reduction of some prochiral ketones in the presence of (-)- $N, N^{\prime \prime}$-dimethylquininium tetrafluoroborate at mercury cathode. Tetrahedron: Asymmetry 14(8):1079-1081

22. Vago M, Williams FJ, Calvo EJ (2007) Enantioselective electrocatalytic hydrogenation of ethyl pyruvate on carbon supported Pd electrodes. Electrochem Commun 9:2725-2728

23. Vasudevan D, Kennady CJ (2008) Electroreduction of carbonyl compounds at a Ti/ceramic $\mathrm{TiO}_{2}$ cathode. J Appl Electrochem 38:403-408

24. Tascedda P, Dunach E (2000) Electrosynthesis of cyclic carbamates from aziridines and carbon dioxide. Chem Commun 6:449-450

25. Batanero B, Saez R, Barba F (2009) Electroreduction of quinones under aprotic conditions. Electrochim Acta 54:4872-4879

26. Zhao HB, Tian H, Jin YH, Cao XJ (2010) Synthesis of 7-ketolithocholic acid via indirect electrooxidation of chenodeoxycholic acid. J Appl Electrochem 40(7):1307-1316

27. Ma XL, Cao XJ (2014) Separation of ursodeoxycholic acid by silylation crystallization. Bioresources and Bioprocessing 1:5

28. Hecht M, Fawcett W (1995) Solvent effects in the electroreduction of [diamine-N, N'-polycarboxylato] chromate (III) complexes at a mercury electrode. J Electroanal Chem 396:473-483

29. Fawcett W (1997) The role of the metal and the solvent in simple heterogeneous electron transfer reactions. Electrochim Acta 42(5):833-839

30. Yuan XX, Ma XL, Cao XJ (2014) Preparation of ursodeoxycholic acid by direct electro-reduction of 7-ketolithocholic acid. Korean J Chem Eng 31(7):1276-1280

\section{Submit your manuscript to a SpringerOpen ${ }^{\circ}$ journal and benefit from:}

- Convenient online submission

- Rigorous peer review

- Immediate publication on acceptance

- Open access: articles freely available online

- High visibility within the field

- Retaining the copyright to your article

Submit your next manuscript at $\gg$ springeropen.com 